\title{
IV. Description of a parabolic sounding board, erected in Attercliffe Church
}

\section{Rev. John Blackburn M.A.}

To cite this article: Rev. John Blackburn M.A. (1829) IV. Description of a parabolic sounding board, erected in Attercliffe Church , Philosophical Magazine Series 2, 6:31, 21-27, DOI: 10.1080/14786442908675051

To link to this article: http://dx.doi.org/10.1080/14786442908675051

$$
\text { 册Published online: } 13 \text { Jul } 2009 .
$$

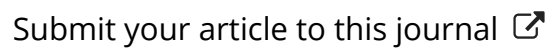

Џ Article views: 2

Q View related articles $₫$ 
I may also just remark, that the rotation of the earth on its axis from W. to E. appears somewhat analogous to certain phænomena in electro-magnetism.

Geology has perhaps hitherto heen considered too much as an insulated science; whereas, I believe that the phrnomena it embraces are only additional links in the chain of creation, so intimately connected in all its parts. Otherwise it must be admitted to present an anomaly when compared with the other works of the Deity, in the minutest portions of which, order, wisdom, and reciprocal dependence become more and more evident in proportion as they are investigated.

\section{Robert W. Fox.}

IV. Description of a Parabolic Sounding Board, erected in Attercliffe Church. By the Rev. John Buackburn, M.A., late of St. John's College, Cambridge; and Minister of Attercliffe-cum-Darnall *.

[With a Plate.]

IN the year 1826 a new church was consecrated at Attercliffe, near Sheffield; being built according to a design by the late ' $T$. Taylor, Esq., by means of a grant from His Majesty's Commissioners appointed under the Act for the building and promoting the building of additional Churches.

The area of the interior is in the form of a rectangular parallelogram, 95 feet by 72. At the east end is an elliptical recess 32 feet wide and 10 feet deep, making the extreme length of the centre line from east to west 105 feet. The roof is vaulted and groined; the highest point in the ceiling of the nave about 56 feet from the plane of the foor: there are galleries at the sides and at the west end.

In this church the resonance was powerful, but the sound indistinct and confused, whatever was the character of the voice from which it proceeded: no exertions, no pains on the part of the speaker could render him audible. To remedy this most serious inconvenience, various unsuccessful experiments were made. The pulpit was removed to different points; and although its present situation proved the best + , the evil complained of still remained : the common horizontal sounding board was tried, which conferred indeed a benefit on a few seats about the pulpit, (seats which least of all re-

* Communicated by the author.

+ The pulpit stands in the middle aisle, 15 feet in advance of the altar rails; its form is octagronal; its floor 9 feet above the floor of the church; the ascent is by a winding staircase, with the dour on one side; in front are the reading-desk and clerk's-desk. 
quired such aid,) but its general effect was so decidedly disadvantageous, that it was again taken down *.

The desired object was to convey a distinct sound to remote parts of the church: under the impression that this might be attained by intercepting so much of the sound as escaped behind and echoed in this part of the vaulted roof; as also by giving it a right direction; and conceiving that a parabolic figure might be so applied as to answer these ends, the writer of this paper made the trial; and the issue has more than realized his hopes and expectations.

Grateful for this result, believing that the application of the principle was new, hoping to awaken the attention of others better qualified than himself (for he does not pretend to much mathematical science or knowledge of acoustics), and induce them to pursue the investigation of this interesting and important, but perhaps neglected, subject, - he addressed a paper to the Royal Society, which was kindly received and honoured with a place among the records of that distinguished insti.tution. Since this communication to the Royal Society, inquiries having been made in every variety of form as to the construction and effect of the parabolic sounding board, a more detailed account is now presented to the public, as the most effectual means of supplying the information required. Those who wish to satisfy themselves by personal view will receive every attention.

The material is pine wood. The surface is concave, and is generated by half a revolution of one branch of a parabola on its axis.

The distance from the focus to the vertex $=2$ feet.

The length of the abscissa is . . . . = 4 feet.

The length of the ordinate to the axis.$=\sqrt{32 \text { feet. }}$

$=$ nearly 5.7

$=$ rad. of outer circle.

The axis is inclined forwards to the plane of the floor at an angle of about 10 or 15 degrees, and elevated so as that the speaker's mouth may be in the focus.

A small curvilinear section is taken away on each side from beneath, that the view of the preacher from the north and south galleries may not be intercepted; whence the outer semicircle is imperfect.

* This follows of course, on the principle that the angle of incidence is equal to the angle of reflection; and yet the horizontal board is that always in use: whence many persons have assumed that no sounding board could he adopted with advantage in any church. 
Sounding Board erected in Attercliffe Church.

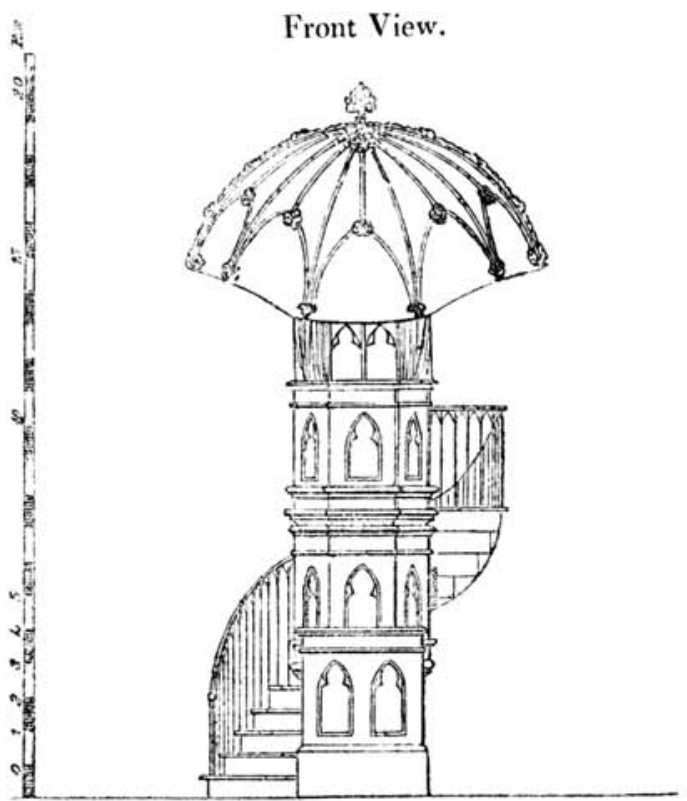

Side View.

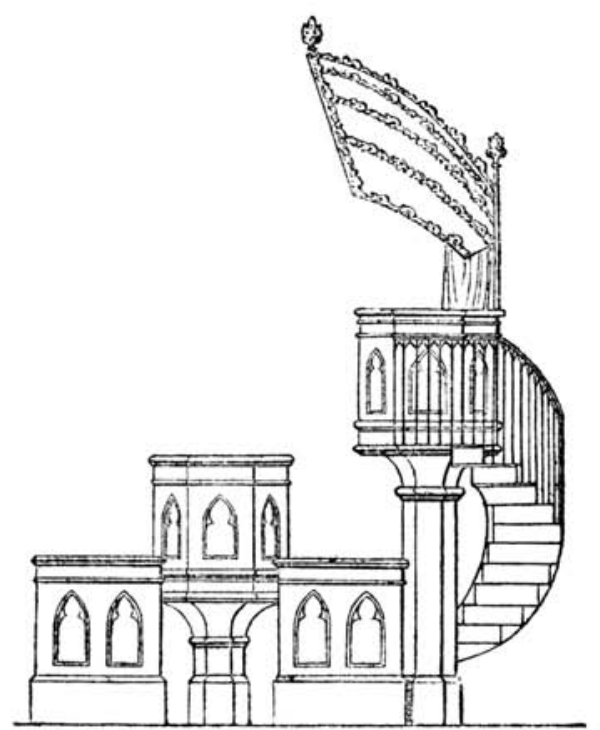


This, however, gives an appearance that is not inelegant; and the outer edge being ornamented with crockets and leaves and with a finial at the highest point, and the concave surface being painted in imitation of a groined oak canopy, the effect of the whole is pleasing to the eye. A curtain is suspended

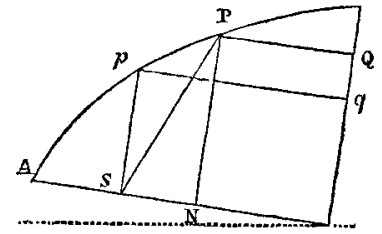
from the lower edge of the canopy for about 18 inches on each side; the object of this is to intercept the sound which would pass beneath the sounding board, and might create a confusion behind : but to press it into the service as proposed hereafter is of course to be preferred.

By means of this erection the volume of sound is increased in a very considerable ratio, and is thrown powerfully, as well as distinctly, to the most distant parts of the church; so that whereas formerly the difficulty of hearing an intelligible sound was very great, now that difficulty is effectually removed.

The preacher was scarcely audible even in the pews near the pulpit, and not at all in those more remote: he may now be heard in every part.

It should seem that the voice is reflected in a direction parallel to the axis; for let $\mathbf{A}$ stand in the pulpit, and B stand first in the west gallery opposite to the pulpit, and then in the side galleries; though $B$ is much nearer to $A$ in the latter case than in the former, he can yet hear with decided advantage when opposite to $A$ (i. e. at the greater distance from him).

The side galleries appear to be benefited rather by the increased volume of sound, and by the secondary vibrations excited in a lateral direction.

It appears also that vibrations proceeding from a distant point and moving in the direction of the axis, are reflected from the parabolic surface towards the focus. For let $A$ stand in the pulpit as before, and $B$ in a distant point opposite to A, A can then converse with $B$ in a whisper; whilst C, standing at an intermediate point, cannot at all distinguish the words spoken by $B$; he can however hear what is said by A. Also if B, at a distance, opposite to the sounding board, speaks; whilst A places one ear in the focus of the parabola and one ear towards B, the effect produced is that of a voice close to the ear, and in a direction the reverse of that from which it really proceeds.

The converse of this also appears true from the following experiment. 
Let $B$ remain in the situation last supposed, and let A place his face towards the parabolic surface, and his back towards $B$; let A now speak, having his mouth in the situation of the focus, and he will be heard as distinctly as when his face was turned towards $B$.

If the mouth of the speaker is placed much within or without, above or below the focus, the effect is proportionably diminished. It has been asked if the speaker must necessarily be confined to one point: to this it may be replied certainly not. He may consult his ease, and will still find the advantage of the canopy over his head; but as his mouth approaches the focus, an attentive hearer will perceive an effect that may not unaptly be compared to the gentle swell of an organ (parvis componere magna). The greater the distance between the focus and the vertex, the less will this variation be perceived.

This sounding board is equally well adapted for a strong or weak voice; the latter acquires strength, whilst in both cases distinctness of articulation is preserved: this may perhaps in some measure be accounted for thus. Assuming that the sound issuing from the focus is reflected in a direction parallel to the axis; assuming also that the velocity of sound is uniform; then the vibrations of the air proceeding from the focus and striking the parabolic surface, at whatever point, will arrive at the same moment of time at a plane perpendicular to the axis. For (according to the properties of the parabola) the sums of the distances (from the focus to the paraboloid, and from the paraboloid to the plane so situated) are always equal to each other: it must however be admitted, that the velocity of sound is too great to allow much dependence to be placed on this conclusion; but it is here proved beyond dispute, that a parabolic surface is capable of being successfully applied to the purpose of a sounding board: whether other concave surfaces similarly situated would be equally successful*, or other materials better adapted to answer the end than pinet, it might be worth while by experiment to ascertain. It is clear that unless the sounding board be constructed with mathematical nicety and placed with mathematical precision, much of the effect will be lost.

Whilst the figure of the canopy remained perfect, the effect was most complete : perhaps it might be improved if constructed larger, or in other words, if continued further in

* Many persons have expressed a preference for the hyperbolcid, as giving a divergency to the rays: one friend has proposed a logarithmic curve.

+ Some have suggested stone, or a frame-work covered with Roman cement; because such a piece of work would not vibrate, and consequently would not counteract the vibration of the air, on which the sound depends.
N.S. Vol. 6. No. 31. July 1829.
E
advance; 
advance; but the distance from the focus to the vertex (which regulates the curve) must depend on the supposed situation of the speaker, which will vary according to the diameter of the pulpit.

The outline, No. 2, represents an improved parabolic sounding board, formed by an entire revolution of the parabola on its axis, with pulpit, reading-desk, and clerk's-desk, according to a model designed and arranged by the writer of this paper, and deposited with the Society of Arts, together with a model of sounding board, No. 1.

The ornamental parts may, of course, be adapted to the character of the building in which it stands: the altar table might be placed in front.

The reflection of sound from the lower part would take the same direction as that from the upper, viz. parallel to the axis: and the effect would probably be much more than double that produced by sounding board, No. 1. Many improvements may still doubtless be suggested.

In erecting a new church, might it not be found most advantageous to give to the east end of the building itself the form of a paraboloidal concave, and to place the pulpit in the focus?

The sounding board, No. 1, was thus constructed. The curve was first drawn according to the following method:On the straight line $\mathrm{LN}$ (fig. 6.) $\mathrm{m}$ ake $\mathrm{LA}=\mathrm{AS}=\mathrm{SN}$. At the point $A$ draw $A B$ perpendicular and equal to $A L$. Join $L B$. Produce $\mathrm{LB}$ to $\mathrm{C}$. Divide $\mathrm{AN}$ into any number of equal parts in $a, b, c, \& c_{\text {. }}$; and at $a, b, c, \& c$. draw $a a, b b, c c, \& c$. parallel to $\triangle \mathrm{B}$, and meeting $\mathrm{LC}$ in $a, b, c$, \&c. Let straight lines = AB, $a a, b b, c c$, \&c. revolve round $\mathrm{S}$ as a centre, intersecting $\mathrm{AB}, a a, b b, c c, \& \mathrm{c}$. respectively in $\mathrm{A}, p, q, r, \& \mathbf{c}$. Join $\mathrm{A}, p, q, r, s, t, \& \mathrm{c}$, and the curve traced out will be a parabola; of which $A$ will be the vertex, $S$ the focus, $A N$ the axis. The distance between the speaker's mouth and the back of the pulpit being 2 feet $=A S=S N=A L$.

Another method is subjoined, being taken from the Mechanics' Weekly Journal, No. XXIV.

"The parabola being the curve that is best adapted for the reflection of heat, and of course requisite for the formation of metallic mirrors, covings of chimneys, and cupolas of melting furnaces; an easy method of describing it, adapted to the comprehension of workmen, was wanted.

"Mr. Leslie, in his "Enquiry into the Nature and Propagation of Heat,' having occasion for metallic mirrors, described the gauges for them in the following manner.

"Let $\mathrm{AB}$ (fig. 7.) denote the extreme breadth, and $\mathrm{CD}$ the intended 
intended depth. Divide $A B$ into 20 parts, and draw perpendiculars from each division. Consider the depth $\mathrm{CD}$ as equal to 100 . Make the next ordinate, or perpendicular, or either side equal to 9 multiplied by 11 , that is to say 99 , by the same scale; which is easily done by the line of lines on a sector rule: the next ordinate on either side equal to 8 multiplied by 12 , that is to say 96 ; and so on. These numbers being respectively as the rectangles of the segments into which $\mathrm{CD}$ is divided."

A scaffolding was made of three semicircles (fig. 4.), $\mathrm{KL}$, $\mathrm{MN}, \mathrm{PZ}$; fixed perpendicular to the axis of the parabola; the axis passing through their centres. This done, three parabolic sectors (fig. 1.), AB, AC, AD, were cut out of three-inch pine and placed as in fig. 1., pointed at the bottom; these were let into two cross ribs, EF, GH, cut out of tough wood naturally bent (to avoid crossing the grain), and dovetailed at each end to keep the three sectors firm and in their place: the spaces between IC, CB, BD, DK, were filled up with sectors cut out of $1 \frac{1}{2}$ inch wood, nailed and glued well together: lastly, the inside was cleaned off and proved by the sector (fig. 6). At regular distances, three iron plates or bands were let in (both inside and outside), well fastened with screws. The horizontal edge IAK was finished with two sectors of hard wood; and the back strengthened where the points chiefly met, with a tough piece of inch board; where also the sounding board was fastened to the pulpit-back with screw-bolts and nuts, being further supported near the centre of gravity by an iron rod suspended from the ceiling above.

The wood was well seasoned, and placed beside a furnace for six weeks; the sounding board has been fixed for nine months, and has not been affected by weather.

Figs. $2 \& 3$ represent the cross ribs EF, GH in fig. 1.

Fig. 5 represents a parabolic sector whose concave is that required.

Fig. 6 represents a parabolic sector whose convex answers to the concave of fig. 5 ; and is used to prove the work when done, being applied at the point $A$, and turned on its axis $\mathrm{AZ}$.

Attercliffe Parsonage, near Sheffield, February 28, 1829. 


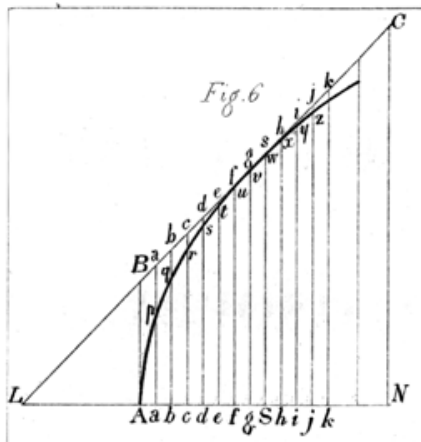

PHIL. MAG.L ANWILS N.S. WOL.6.PL.

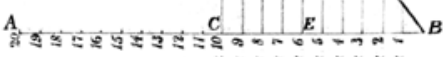

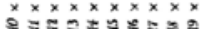

1 11 11 प1 11

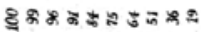
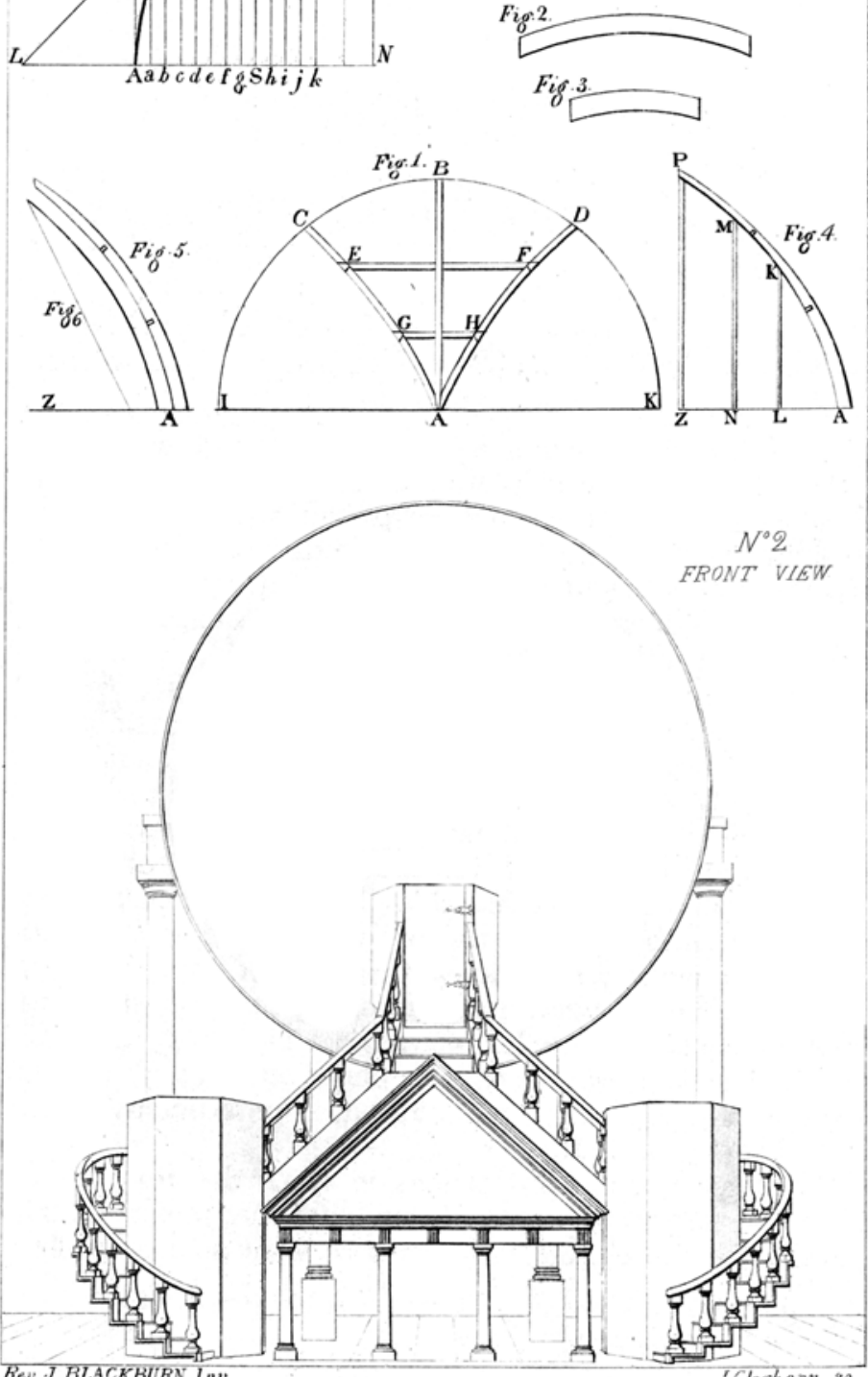